\title{
MODEL KERANGKA KERJA SOSIALISASI IDENTITAS BARU JAKTV
}

Tiara Pratiwi, Ina Novita Sari, Yuliana Riana Prasetyawati

STIKOM The London School of Public Relations

Email: tiara.pratiwi84@gmail.com, inanovita97@gmail.com, yuliana.rp@lspr.edu

\begin{abstract}
ABSTRAK
Perkembangan pasar dan pengubahan gaya hidup audience umumnya menuntut perusahaan untuk beradaptasi seperti dilakukannya repositioning terhadap target market dan citra perusahaan untuk menjaga eksistensi serta memperluas pangsa pasar, salah satu upaya yang dilakukan yaitu pengubahan identitas perusahaan. Industri televisi menjadi salah satu industri yang terdampak, karena kini masyarakat bisa menyaksikan tayangan televisi melalui handphone. Akibat hal tersebut, JAKTV turut melakukan pengubahan identitas perusahaan berupa pengubahan logo dan tagline serta menjalankan proses sosialisasi sejak 1 Januari 2018. Penelitian ini bertujuan untuk menganalisa dan mengevaluasi implementasi taktik public relations dalam menyosialisasikan logo dan tagline baru JAKTV. Teori rebranding dan konsep public relations tools digunakan untuk menganalisa kegiatan sosialisasi dengan metode penelitian kualitatif deskriptif melalui wawancara mendalam dengan teknik wawancara terstruktur kepada tim public relations JAKTV hingga salah satu pemirsa JAKTV sebagai metode pengumpulan data, sementara metode pengambilan sampel quota sampling yang dilakukan kepada pihak internal dan eksternal perusahaan sehingga menghasilkan 5 narasumber. Penelitian ini menghasilkan model kerangka kerja dari proses sosialisasi identitas baru JAKTV. Disarankan agar peneliti selanjutnya dapat melakukan penelitian mengenai persepsi dari target publik JAKTV terhadap repositioning JAKTV dari MY CITY MY TV menjadi Dari Jakarta untuk Indonesia.
\end{abstract}

Kata Kunci: model kerangka kerja; repositioning; sosialisasi; identitas baru; JAKTVa 


\begin{abstract}
Market developments and changing lifestyles of the audience generally require companies to adapt as they do repositioning of the target market and corporate image to maintain their existence and expand market share, one of the efforts is changing the company's identity. The television industry has become one of the affected industries because now people can watch television shows via mobile phones. As a result, JAKTV also changed the company's identity in the form of logo and tagline changes and running the disseminating process since January 1, 2018. This research aims to analyze and evaluate the implementation of public relations tactics in disseminating process of JAKTV's new identity. The rebranding theory and public relations tools concept is use to analyze the disseminating process of JAKTV's new identity with descriptive qualitative through in-depth interviews with structured interview techniques, while the quota sampling is carried out to JAKTV internal and external parties to produce 5 informants. The results is a framework for JAKTV's new identity dissemination model. It's recommended for this research is that further researchers be able to research the perception of JAKTV's public target towards repositioning JAKTV as from Jakarta to Indonesia.
\end{abstract}

Keywords: framework model; repositioning; dissemination; new identity; JAKTV 


\section{PENDAHULUAN}

Perkembangan pasar dan pengubahan gaya hidup audience umumnya menuntut perusahaan untuk mampu beradaptasi. Adakalanya pengubahan ini berujung pada dilakukannya repositioning terhadap target market dan citra perusahaan untuk meraih kepercayaan dari masyarakat, tetap dapat bersaing, menjaga eksistensi, serta memperluas pangsa pasar.

Repositioning ini menjadi penting untuk perusahaan karena perusahaan akan terbantu dalam proses penentuan company brand yang baru dalam benak masyarakat. Jika repositioning yang ditentukan jelas, maka akan terbentuk citra positif dalam benak masyarakat. Pengubahan identitas perusahaan diantaranya logo dan tagline harus dikenal dan di ingat oleh masyarakat agar hal ini dapat membuat perusahaan memenangkan kompetisi di pasar.

Pengubahan ini perlu disosialisasikan dengan baik dan efektif kepada pihak internal dan eksternal perusahaan agar upaya perusahaan melakukan repositioning terhadap target market dan citra perusahaan dapat terwujud serta tercipta brand image baru di benak masyarakat yang sesuai dengan keinginan perusahaan. Melalui pemilihan citra serta taktik sosialisasi yang tepat, maka akan berdampak pada pertambahan jumlah audience perusahaan yang akan membuat audiensi perusahaan semakin variatif.

Namun jika citra yang dipilih tidak tepat, maka dapat menimbulkan kontra di masyarakat seperti yang terjadi pada kota Purbalingga di tahun 2017, dimana Bupati Purbalingga mengganti slogan atau tagline "Purbalingga Perwira" menjadi "Purbalingga Sehati” hingga lahirnya sebuah petisi pada situs Change.org dari seorang warga Purbalingga yang di dasari atas sikap penentangan masyarakat terhadap pengubahan slogan atau tagline yang sangat melekat pada para birokrat juga masyarakat Purbalingga (Purbalingga Sehati Dilauncing, Purbalingga Tidak Lagi Perwira, 2017 ; Ridlo, 2017).

Maka sebab itu, pemilihan taktik yang tepat dalam menyosialisasikan repositioning terhadap logo dan tagline baru perusahaan menjadi salah satu fokus utama bagi praktisi public relations dalam upaya membuat masyarakat memiliki kesamaan paham dengan apa yang perusahaan inginkan.

Industri televisi menjadi salah satu perusahaan yan turut terdampak kini masyarakat tidak lagi menyaksikan televisi dengan duduk menghadap layar melainkan menggunakan tayangan video sambil jalan (Satryatomo, 2017).

Akibat hal tersebut, JAKTV turut melakukan pengubahan pada identitas perusahaannya yaitu pengubahan pada logo dan tagline yang dilakukan pada 1 Januari 2018, dengan 
mengubah font dan warna logo JAKTV menjadi lebih tegas dan sederhana dan membuat tagline baru berbunyi Dari Jakarta Untuk Indonesia.

Gambar 1. Logo dan Tagline Lama JAKTV dari (JAKTV, n.d)

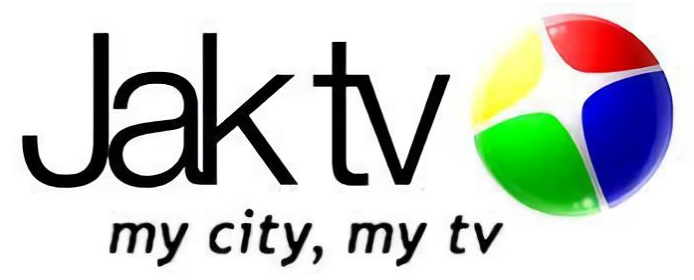

Gambar 2. Logo dan Tagline Baru JAKTV dari (JAKTV, n.d).

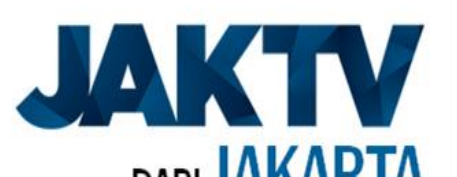

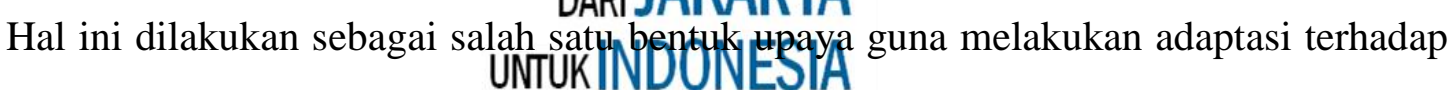

perkembangan pasar dan pengubahan gaya hidup audience yang kini lebih banyak menyaksikan tayangan televisi melalui layanan internet. Setelah selama lebih dari 5 tahun JAKTV menggunakan logo dengan simbol lingkaran empat warna (merah, kuning, hijau, dan biru) dan tagline My City, My Tv yang telah digunakan selama 12 tahun.

Langkah repositioning ini di ambil karena JAKTV ingin melakukan penyegaran terhadap kedua identitas perusahaan tersebut, di samping itu juga sebagai cara untuk mempertegas positioning JAKTV bahwa JAKTV bukan lagi brand yang dimiliki oleh masyarakat sekitar Jakarta saja namun kini JAKTV menjadi sebuah brand yang di miliki oleh seluruh masyarakat Indonesia.

Kepemirsaan JAKTV yang semakin variatif dari segi geografis menjadi salah satu faktor dilakukannya repositioning terhadap target market serta citra perusahaan JAKTV (Zainufry dan Kurnia, komunikasi pribadi, 16 Oktober 2018).

Sosialisasi logo dan tagline sebagai bentuk dari adaptasi JAKTV terhadap perkembangan zaman ini pun dilakukan atas latar belakang bahwa JAKTV ingin memperluas jangkauan siar ke seluruh Indonesia melalui jaringan TV berbayar dan online streaming di platform online seperti Hooq, Youtube channel JAKTV, mivo.tv, useetv.com, dan Vidio.com (Zainufry, komunikasi pribadi, 16 Oktober 2018).

Sebagai salah satu usaha untuk menyebarluaskan repositioning target market dan citra baru perusahaan melalui pengubahan dua identitas perusahaan yaitu logo dan tagline, JAKTV 
melakukan pemilihan taktik public relations yang tepat untuk akan dimanfaatkan guna membantu tim public relations dalam pelaksanaan rencana komunikasi yang telah dirancang.

Pemilihan taktik public relations yang tepat ini penting agar tercipta kesamaan paham antara JAKTV dengan publik internal maupun eksternal terkait makna pesan yang terkandung di dalam logo dan tagline baru tersebut. Sehingga pemilihan taktik public relations ini tidak menjadi bumerang tetapi menguntungkan perusahaan di kemudian hari.

Guna menjawab persoalan terkait sosialisasi identitas baru JAKTV, maka penelitian ini di buat dengan tujuan untuk menganalisis serta mengevaluasi hasil implementasi pemanfaatan taktik public relations yang tergambar dalam model kerangka kerja dari proses sosialisasi identitas baru JAKTV.

\section{Metodologi Penelitian}

Pada penelitian ini digunakan konsep utama the $7 C$ 's of Communications serta public relations tools sebagai konsep pendukung guna mengakomodasi penggambaran pengimplementasian dari pemanfaatan taktik public relations yang tergambar dalam model kerangka kerja dari proses sosialisasi identitas baru JAKTV.

Peneltian ini menggunakan pendekatan penelitian kualitatif dengan jenis penelitian deskriptif dengan menggunakan paradigma konstruktivis.

Pendekatan penelitian kualitatif menurut Creswel (1994) merupakan suatu proses penelitian yang digunakan untuk memahami berbagai masalah sosial atau permasalahan manusia berdasarkan gambaran yang menyeluruh dan kompleks, yang tersaji dengan menggunakan kata-kata, dilaporkan melalui pelaporan informasi secara terperinci yang di dapat dari para narasumber di mana proses pengumpulan data ini dilakukan dalam latar (setting) yang alamiah.

Sedangkan jenis penelitian deskriptif merupakan suatu penelitian yang mencoba mendefinisikan dan menjabaran masalah dengan menggunakan kata - kata atau angka untuk menyajikan sebuah gambaran yang berfokus pada jawaban dari pertanyaan mengenai aktifitas sosial tentang siapa, kapan, dimana, dan bagaimana (Neuman, 2014, p.38). Jenis penelitian ini digunakan karena memungkinkan peneliti dalam menggambarkan hasil implementasi pemanfaatan taktik public relations yang tergambar dalam model kerangka kerja dari proses sosialisasi identitas baru JAKTV. 
Sementara paradigma konstruktifis merupakan suatu paradigma atau cara berpikir yang melihat bagaimana kebenaran sebuah realitas sosial merupakan hasil dari konstruksi sosial yang bersifat relative, yang mana individu mengembangkan makna yang subjektif terhadap pemaknaan dari pengalaman yang di dapatkan mengenai suatu benda atau peristiwa (Eriyanto, 2004, p.13). Paradigma ini digunakan oleh peneliti karena peneliti dapat melakukan penganalisaan serta pengevaluasian hasil implementasi pemanfaatan taktik public relations yang tergambar dalam model kerangka kerja dari proses sosialisasi identitas baru JAKTV.

Peneliti menggunakan metode wawancara mendalam (in-depth interview) dengan tekhnik wawancara terstruktur sebagai tahap pengumpulan data dengan ketentuan bahwa berbagai pihak yang akan menjadi narasumber haruslah pihak - pihak yang terlibat maupun yang menerima informasi mengenai topik penelitian ini.

Metode wawancara mendalam (in-depth interview) merupakan suatu tekhnik untuk mendapatkan informasi yang di anggap tidak dapat terjawab melalui penyebaran kuesioner. Dimana diskusi yang terjadi antara peneliti dengan narasumber merupakan diskusi yan terarah terkait dengan masalah penelitian dengan menggunakan jenis pertanyaan terbuka, sehingga memungkinkan bagi peneliti untuk mendapatkan berbagai variasi jawaban sesuai dengan pemikiran narasumber (Danim, 2000, p.17).

Sementara tekhnik wawancara terstruktur merupakan suatu tekhnik yang disarankan oleh Guba dan Lincoln apabila peneliti menyadari apa yang tidak diketahui oleh peneliti, oleh karena itu peneliti berada di dalam posisi untuk membingkai pertanyaan yang dapat menyediakan informasi yang dibutuhkan terkait hal yang di teliti (Cohen, Manion \& Marrisson, 2007, p.354).

Metode non-probability sampling dengan teknik quota sampling digunakan sebagai metode dan teknik pengambilan sampling pada penelitian ini. Sugiono (dalam Yusiana \& Maulida, 2015) metode non probability sampling merupakan metode pengambilan sampel yang tidak memberikan kesamaan peluang atau kesempatan kepada seluruh anggota populasi untuk dapat dipilih menjadi sampel sementara teknik quota sampling adalah teknik pengambilan sampel yang dilakukan dengan cara melakukan pengidentifikasian terhadap berbagai kriteria yang memiliki relevansi dengan hal yang diteliti serta mementukan jumlah sampel yang akan diambil (Neuman, 2014, p.249)

Berdasarkan metode pengambilan sampel tersebut maka narasumber dalam penelitian ini yaitu (1). Group Head Public Relations And Off Air Promotion Department, Ikhwansyah Lufiara; (2) Department Head Postpro-Graphic And On Air Promotion Department, Achmad 
Bagus Kurnia; (3) Staff Content Management Department, Jehan Julianti; (4) Department Head Public Relations And Off Air Promotion Department Periode 2005 - 2018, Achmad Zainufry; 5) Pemirsa JAKTV, ibu Sutartinah.

Dalam penelitian ini triangulasi sumber digunakan sebagai teknik verifikasi informasi. Sugiyono mengungkapkan triangulasi sumber merupakan suatu teknik verifikasi informasi yang digunakan untuk memperoleh data dari berbagai sumber namun dengan teknik yang sama (2013, p.330).

Teknik verifikasi informasi yang digunakan dalam penelitian ini yaitu triangulasi sumber yang membandingkan data yang di dapat melalui hasil wawancara kepada tiga narasumber berbeda.

Penelitian yang dilakukan pada bulan September 2018 hingga Juni 2019 ini menggunakan model analisa data Miles and Huberman, yang terdiri dari 1) reduksi data atau ; 2) penyajian data; 3) penarikan kesimpulan atau verifikasi (Miles, Huberman \& Saldana, 2014).

Proses adaptasi perusahaan terhadap perkembangan pasar dan pengubahan gaya hidup audience terkadang mengharuskan perusahaan untuk melakukan repositioning terhadap citra dan target market perusahaan. Kotler menerangkan (dalam Shesarria \& Gitasiswhara, 2012) bahwa positioning merupakan suatu kegiatan yang dilakukan dalam rangka mendesain citra perusahaan guna mendapatkan posisi yang berbeda dalam persaingan pasar yang bertujuan untuk memaksimalkan potensi manfaat yang akan di dapat oleh perusahaan.

Hermawan Kartajaya pun menuturkan bahwa positioning pada hakikatnya adalah upaya atau janji yang dibuat dan dilakukan oleh perusahaan untuk meyakinkan dan membuat konsumen percaya kepada perusahaan bahwa dalam keadaan pasar yang terus berkembang, perusahaan mampu untuk terus mengikuti permintaan dan pengubahan gaya hidup audience. Salah satu upaya yang dapat dilakukan terkait hal ini yaitu melakukan repositioning (Shesarria \& Gitasiswhara, 2012).

Muzzellec dan M.C Lambkin merinci kegiatan yang dilakukan dalam rangka repositioning salah satunya melibatkan pengubahan logo dan tagline perusahaan, nama perusahaan, citra, renovasi bangunan, kinerja staff ataupun strategi marketing dan tema iklan (Shesarria \& Gitasiswhara, 2012). Pada penelitian ini kegiatan yang dilakukan dalam rangka repositioning yaitu pengubahan logo dan tagline perusahaan yang dilakukan oleh JAKTV. 
Repositioning ini perlu diimplementasikan dengan menentukan taktik public relations yang dapat dimanfaatkan dengan tepat agar proses penyosialisasian terhadap pengubahan logo dan tagline JAKTV dapat berjalan sesuai dengan yang diharapkan oleh perusahaan.

Maka diperlukan sebuah rencana komunikasi yang efektif dengan memperhatikan berbagai unsur yang terangkum dalam konsep the $7 C$ 's of communications, diantaranya yaitu (1) kredibilitas atau credibility, dikatakan bahwa komunikasi di mulai melalui iklim yang saling percaya, di mana receiver harus memiliki kepercayaan kepada sender dan menghormati kompetensi sumber informasi terhadap topik informasi. (2) konteks atau context, unsur ini menjelaskan bahwa rencana komunikasi yang di buat harus sesuai dengan kenyataan lingkungan agar terjadi komunikasi yang efektif. (3) konten atau content, dijelaskan bahwa pesan yang ingin disampaikan harus mengandung makna dan relevan dengan situasi receiver. (4) kejelasan pesan atau clarity, disampaikan juga bahwa pesan yang ingin disampaikan harus memiliki istilah yang mudah di pahami dan memiliki kesamaan makna antara sender dengan receiver. (5) kesinambungan isi pesan dan konsistensi atau continuity and consistency, dijelaskan bahwa dalam menyampaikan suatu pesan maka harus ada pengulangan atau repitisi terhadap isi pesan yang dilakukan secara konsisten. (6) media komunikasi atau channel, pemilihan media komunikasi di sesuaikan dengan publik di mana media komunikasi ini merupakan media komunikasi yang di hargai dan dipakai oleh receiver. (7) kemampuan audience atau capability of the audience menjadi unsur terakhir yang harus diperhatikan oleh public relations JAKTV dalam proses sosialisasi logo dan tagline ini karena dikatakan bahwa proses komunikasi yang terjadi harus mempertimbangkan kemampuan audience, yang mana kemampuan ini yang di pengaruhi berbagai faktor seperti ketersediaan waktu, kebiasaan, kemampuan membaca dan pengetahuan awal (Cutlip, Center, \& Broom, 2011).

Pemilihan taktik public relations yang tepat pun perlu direncanakan oleh tim public relations JAKTV agar dapat mengakomodasi rencana komunikasi yang telah disusun. Pemilihan taktik public relations yang dapat dipertimbangkan yaitu (1) special event yang terdiri dari (a) open house atau company visit, yang merupakan tools bagi praktisi public relations untuk memberikan kesempatan untuk berkunjung langsung ke perusahaan kepada publik guna mengenal perusahaan lebih dekat. (b) award ceremony, tools yang digunakan untuk kegiatan pemberian penghargaan terhada sesuatu kepada orang - orang tertentu. (2) Thank you notes and letters, Alat kegiatan ini berupa ucapan - ucapan terimakasih yang ditujukan kepada publik atas dukungannya terhadap perusahaan. (3) Audio-visual instrument, Alat kegiatan ini dapat berupa pembuatan company profile berbentuk audiovisual dan materi 
persentasi di hadapan publik. (4) Sponsorships atau Patnerships, Media public relations ini berupa kegiatan menjadi sponsor atau partner di berbagai acara (Kriyantono, 2012, p.28-32).

\section{Hasil Penelitian Dan Pembahasan}

Sebagai salah satu perusahaan yang bergerak di industri penyiaran televisi lokal, yang telah mengudara sejak tahun 2005, JAKTV memutuskan untuk melakukan repositioning dengan membuat penyegaran terhadap logo dan tagline pada 1 Januari 2018. Hal ini dilatar belakangi oleh keadaan pasar yang semakin berkembang serta perluasan sebaran audience JAKTV yang pada akhirnya menuntut perusaaan untuk mampu beradaptasi (Zainufry, komunikasi pribadi, 16 Oktober 2018).

Repositioning yang dilakukan dengan pengubahan pada logo dan tagline JAKTV bertujuan untuk mempertegas posisi JAKTV bahwa JAKTV ingin dikenal tidak lagi sebagai brand yang dimiliki oleh masyarakat sekitar Jakarta saja namun sebagai sebuah brand dan televisi yang dimiliki oleh seluruh masyarakat Indonesia. Hal ini dijabarkan oleh Bapak Zainufry kepala department Public Relations And Off Air Promotion Department Periode 2005 $-2018:$

"Kita ingin mempertegas positioning JAKTV bukan lagi brand yang dimiliki oleh masyarakat sekitar Jakarta saja namun JAKTV menjadi sebuah brand yang dimiliki oleh seluruh Indonesia” (Zainufry, komunikasi pribadi, 16 Oktober 2018).

Repositioning ini pun dilakukan guna mengakomodasi hasil evaluasi yang telah dilakukan oleh JAKTV, dimana hasil dari evaluasi tersebut memperlihatkan bahwa terhadap perluasan jumlah sebaran audience yang menyaksikan tayangan JAKTV sehingga perluasan pangsa pasar pun turut dilakukan. Hal ini dilakukan untuk memperlihatkna kepada audience bahwa dengan keadaan pasar yang semakin berkembang, JAKTV mampu untuk tetap terus mengikuti permintaan audience, seperti yang diutarakan oleh Bapak Zainufry:

"Hasil evaluasi yang kita lakukan menunjukan bahwa 60\% pemberitaan di Jakarta itu berskala nasional sehingga yang menyaksikan tayangan tersebut tidak hanya berasal dari Jakarta saja untuk itu kita melakukan perluasan jangkauan siar untuk mengakomodir audience - audience JAKTV yang berasal dari berbagai daerah itu yang dilakukan melalui jaringan televisi berbayar dan online streming" (Zainufry, komunikasi pribadi, 16 Oktober 2018).

Penyegaran yang dilakukan JAKTV terhadap logo dan tagline ini perlu di sosialisasikan kepada publik agar pesan yang ingin disampaikan oleh tim public relations 
JAKTV mengenai repositioning terhadap target market dan citra perusahaan dapat tersampaikan dengan baik. Terkait hal tersebut, maka tim public relations JAKTV perlu untuk merencanakan komunikasi yang efektif.

Berdasarkan hasil analisa pengimplementasian taktik public relations dalam menyosialisasikan logo dan tagline baru JAKTV, maka jika di lihat dari segi (1) kredibilitas atau credibilty, tim public relations JAKTV melakukan proses pengimplementasian taktik public relations dalam menyosialisasikan logo dan tagline baru ini dibantu oleh berbagai pihak baik dari sisi internal maupun eksternal, seperti yang diutarakan oleh Bapak Ikhwansyah selaku Group Head Public Relations And Off Air Promotion:

“Tim digital juga menginformasikan bahwa kita (logo dan taglinenya) sudah berubah. Dari tim purchasing juga mengubah berbagai alat administrasi seperti kertas kop surat, kartu nama. Selain itu kita juga bekerja sama dengan pihak luar seperti group radio, media cetak juga ada" (Ikhwansyah Lufiara, Komunikasi pribadi, 8 April 2019).

Repositioning yang dilakukan oleh JAKTV ini tidak dapat lepas dari pengubahan yang terjadi terhadap lingkungan sosial di sekitar JAKTV, hal ini dapat dilihat melalui (2) konteks atau context, keadaan lingkungan sosial yang turut di dukung oleh perkembangan teknologi disekitar JAKTV membuat semakin variatifnya kepemirsaan JAKTV, yang pada akhirnya membuat JAKTV memutuskan untuk mengubah logo dan tagline sebagai salah satu upaya repositioning. Seperti yang dikatakan oleh Bapak Ikhwansyah Lufiara selaku Group Head dari Public Relations And Aff Air Promotion Department mengungkapkan:

"Pertimbangannya (kenapa mengubah logo dan tagline) karena kita mengikuti perkembangan zamanlah. Saat ini sudah pakai teknologi canggih sehingga jangkauan siar televisi bisa di terima oleh masyarakat di berbagai daerah bahkan di luar negeri. Dan pemirsa JAKTV juga sudah banyak. Bukan hanya di JABODETABEK saja, sudah ada di luar daerah bahkan sampai ke luar negeri juga ada" (Ikhwansyah Lufiara, Komunikasi pribadi, 8 April 2019).

Pernyataan tersebut turut diperkuat oleh salah satu staff dari content management department, Jehan Julianti yang mengungkapkan bahwa: “...satelit yang digunakan oleh JAKTV sudah dapat menjangkau berbagai daerah lain di Indonesia" (Jehan Julianti, Komunikasi pribadi, 8 April 2019).

Bila di lihat dari sisi (3) konten atau content, maka pesan yang ingin di sampaikan oleh JAKTV mengenai pengubahan logo dan tagline baru ini sesuai dengan situasi yang terjadi di 
masyarakat di mana pemirsa JAKTV saat ini tidak lagi berasal dari daerah Jakarta saja. Bapak Ikhwansyah Lufiara menyampaikan:

“...pengubahan JAKTV ini akan bisa di lihat di seluruh Indonesia bahkan di luar negeri. Kalau tagline yang lama kan My City My TV, jadi terbatas hanya bisa di tonton oleh masyarakat JABODETABEK. Tapi yang baru ini kan bisa di siarkan ke seluruh Nusantara, Indonesia bahkan bisa di luar negeri” (Ikhwansyah Lufiara, Komunikasi pribadi, 8 April 2019).

Jika ditinjau dari segi (4) kejelasan pesan atau clarity, maka dapat dikatakan bahwa proses komunikasi yang dilakukan oleh tim public relations JAKTV kepada publiknya sudah efektif. Hal ini terkait persamaan makna yang ditangkap oleh publik yang menjadi sasaran. Seperti yang terlihat dari penuturan Bapak Achmad Bagus Kurnia selaku Kepala Department Postpro-Graphic and On Air Promotion :

"Kita ingin mengakomodasi perkembangan target audience JAKTV yang sudah bukan lagi berasal dari wilayah Jakarta saja tapi sudah berasal dari pelosokpelosok Indonesia bahkan luar negeri seiring perkembangan zaman itu, kita juga ingin tetap bisa bersaing dengan tv-tv lokal ataupun nasional" (Achmad Bagus Kurnia Komunikasi pribadi, 9 April 2019).

Penafsiran pesan serupa turut disampaikan oleh ibu Sutartinah yang menyampaikan

"Menurut saya, yang lama itu menunjukan kalau mimpi dari JAKTV ini ingin stasiun tvnya bisa sampai (menjangkau) ke seluruh orang di Jakarta, sedangkan yang baru ini dia ingin kalau tvnya itu bisa di nikmati oleh seluruh masyarakat Indonesia" (Sutartinah, Komunikasi pribadi, 20 Agustus 2019).

Sebuah komunikasi yang efektif memiliki unsur penyampaian pesan yang (5) berkesinambungan dan konsistensi atau Continuity dan consistency, proses sosialisasi logo dan tagline baru JAKTV ini masih terus berlanjut hingga tahun 2019. Seperti yang di ungkapkan Group Head dari Public Relations And Aff Air Promotion Department, bapak Ikhwansyah Lufiara "tahun ini kita mungkin akan pasang billboard atau videotron, kerjasama juga dengan kita punya group (MAHAKA group). Kemudian juga akan menyosialisasikan ke perguruan tinggi. Kita akan masuk kampus” (Ikhwansyah Lufiara, Komunikasi pribadi, 8 April 2019).

Salah satu unsur penting yang harus diperhatikan agar terjadi komunikasi yang efektif yaitu (6) media komunikasi atau channel, Pemilihan media komunikasi yang di lakukan tim public relations JAKTV telah sesuai dengan media komunikasi yang di gunakan oleh target audiencenya, di mana mereka memilih menggunakan televisi, sosial media, media cetak, radio 
serta direct communication yang dilakukan pada saat rapat internal. Hal ini di jelaskan oleh bapak Ikhwansyah Lufiara selaku Group Head dari public relations and off air department:

"Kita menggunakan direct communication yang terjadi pada saat internal meeting dengan para staff JAKTV dan utamanya kita menggunakan layar televisi kita untuk menyosialisasikan pengubahan logo dan tagline ini kepada pemirsa setia JAKTV, kita pun di bantu oleh tim digital untuk sosialisasi menggunakan sosial media. Untuk masyarakat yang belum tau JAKTV kita menggunakan media cetak dan radio" (Ikhwansyah Lufiara, Komunikasi pribadi, 8 April 2019).

Unsur terakhir yang harus diperhatikan oleh public relations JAKTV dalam proses sosialisasi logo dan tagline ini yaitu (7) kemampuan audience atau capability of audience, para audience yang di targetkan oleh JAKTV dalam proses sosialisasi logo dan tagline baru ini memiliki kemampuan penerimaan pesan yang sama. Hal ini di ungkapkan oleh Bapak Ikhwansyah Lufiara:

"Target (utamanya) 30+ ke atas ya perempuan. Kita sasarin perempuan. Laki - laki juga ada. kita sasarin (utamanya) perempuan karena perempuan itu banyak yang menghabiskan waktunya di depan televisi, tetapi tidak menutup kemungkinan juga untuk yang di bawah usianya 30 tahun" (Ikhwansyah Lufiara, Komunikasi pribadi, 8 April 2019).

Apabila ditinjau dari segi pengimplementasian Public Relations Tools, maka dalam usaha menyosialisasikan pengubahan logo dan tagline sebagai salah satu cara repositioning, tim public relations JAKTV memilih menggunakan tools special events berupa (1a) Open house atau company visit, pada kesempatan ini JAKTV memberikan sosialisasi kepada masyarakat yang datang berkunjung mengenai logo dan tagline barunya. Hal ini di ungkapkan oleh Bapak Ikhwansyah Lufiara: "Kita juga sosialisasi melalui open house atau company visit. Jadi ketika sekolah-sekolah itu datang berkunjung kan kita memperkenalkan JAKTV itu seperti apa, program - program yang kita punya, fasilitasnya, kita juga mensosialisasikan mengenai pengubahan logo dan tagline JAKTV" (Ikhwansyah Lufiara, Komunikasi pribadi, 8 April 2019).

Tools special events selanjutnya yang digunakan oleh tim public relations JAKTV yaitu (1b) Award Ceremony, Special event berupa award ceremony dilakukan JAKTV pada 2018 dalam acara JAWARA JAKTV Awards 2018. Pada acara ini di tayangkan audio-visual material berupa profile masing - masing tokoh yang di dalamnya terdapat logo baru JAKTV. Hal ini di ungkapkan oleh Bapak Ikhwansyah Lufiara : 
"Kita buat JAWARA Awards 2018 kemarin selain untuk memberikan penghargaan kepada para tokoh inspiratif yang terlibat dalam pemberdayaan ekonomi, secara tidak langsung juga mensosialisasikan logo baru JAKTV dari pembuatan materi audio-visual yang di dalamnya kita masukan logo JAKTV yang baru" (Ikhwansyah Lufiara, Komunikasi pribadi, 8 April 2019).

Company profile JAKTV turut menjadi salah satu tools yang digunakan oleh public relations JAKTV dalam pemanfaatan tools (2) audio - visual instrument, tools ini digunakan tidak hanya terbatas di pembuatan video company profile JAKTV saja, namun juga diterapkan di berbagai program tayangan JAKTV, konten-konten media sosial serta berbagai materi presentasi yang di tampilkan pada saat internal meeting dengan para staff dari seluruh department. Bapak Ikhwansyah Lufiara menjelaskan:

"Setiap kita ikut jobfair kan kita selalu bawa layar lcd nah itu gunanya untuk menayangkan company profile yang sudah kita buat, di dalamnya itu kan terdapat logo baru JAKTV jadi kita memperkenalkan logo baru JAKTV itu melalui company profile berbentuk audio-visual yang ditayangkan di acara jobfair itu dan Untuk menyampaikan ke pemirsa (mengenai pengubahan logo dan tagline) yang utama kita melalui layar televisi sendiri agar pemirsa yang sudah setia menjadi pemirsa JAKTV lebih tahu. Sekarang kita gencarkan adalah sosial media. Kita juga menyosialisasikan pengubahan logo dan tagline melalui internal meeting dengan para staff dari seluruh divisi dan mobil-mobil operasional kita di branding dengan logo dan tagline JAKTV" (Ikhwansyah Lufiara, Komunikasi pribadi, 8 April 2019).

Sebagai bentuk ungkapan terimakasih kepada pemirsa JAKTV saat JAKTV menerima penghargaan sebagai televisi nomor 1 mulai dari Desember 2018 hingga April 2019, JAKTV turut menggunakan tools (3) Thank you notes and letters, tools ini digunakan oleh tim public relations JAKTV sebagai bentuk ungkapan terimakasih kepada pemirsa JAKTV saat JAKTV mendapat penghargaan dari Neilsen sebagai televisi nomor satu mulai dari bulan Desember 2018 hingga April 2019. Hal ini diterangkan oleh Bapak Ikhwansyah Lufiara menerangkan: "kita sudah pasang di Kompas bahwa kita terimakasih kepada pemirsa, kita menjadi televisi lokal yang mendapat peringkat pertama dalam 4 bulan berturut-turut. Kita sudah pasang di media Wanita Indonesia, Republika dan di sosial media" (Ikhwansyah Lufiara, Komunikasi pribadi, 8 April 2019).

Tim public relations JAKTV turut menggunakan tools (4) Sponsorhip atau partnership, sebagai upaya pensosialisasikan logo dan tagline baru. Kegiatan ini banyak dilakukan JAKTV 
dengan berbagai acara yang dilakukan oleh pihak eksternal perusahaan serta dengan berbagai media terutama media yang bergabung di bawah naungan Mahaka Group. Hal ini dijelaskan oleh Bapak Ikhwansyah Lufiara selaku Group Head dari Public Relations And Off Air Promotion Department: "Untuk yang belum tau mengenai JAKTV kita menggunakan media luar seperti group radio dan media cetak yang JAKTV punya. Intinya kalau eksternal itu tadi kita menggandeng media luar, dalam arti kata media selain televisi” (Ikhwansyah Lufiara, Komunikasi pribadi, 8 April 2019).

Berdasarkan hasil analisa maka pemanfaatan serangkaian taktik public relations baik di media offline maupun media online yang dilakukan oleh tim public relations JAKTV seperti memanfaatkan taktik berupa special events, thank you notes and letters, audio-visual instrument dan sponsorhip berperan penting dalam proses sosialisasi logo dan tagline baru JAKTV.

Setelah dilakukan proses pengevaluasian oleh tim Public Relations and Off Air Promotion Department terhadap proses sosialisasi identitas baru JAKTV yaitu logo dan tagline, maka dapat di katakan bahwa pemanfaatan taktik public relations berupa audio visual instrument yang diterapkan pada media sosial JAKTV dapat dikatakan cukup efektif serta proses sosialisasi ini membawa pengubahan dalam kevariatifan kepemirsaan JAKTV.

Hal ini seperti yang di ungkapkan oleh Bapak Ikhwansyah Lufiara "Kita gencarkan sosialisasi pengubahan logo dan tagline ini melalui sosial media. Itu lebih ampuh”. Bapak Achmad Zainufry pun mengungkapkan “ $60 \%$ porsi pemberitaan di Jakarta berskala nasional sehingga pemirsa yang menyaksikan tidak hanya berasal dari Jakarta saja” (Achmad Zainufry, Komunikasi pribadi, 16 Oktober 2018). 
Gambar 3. Model Alur Kerja Sosialisasi Identitas Baru JAKTV dari (data olahan peneliti, 2019).

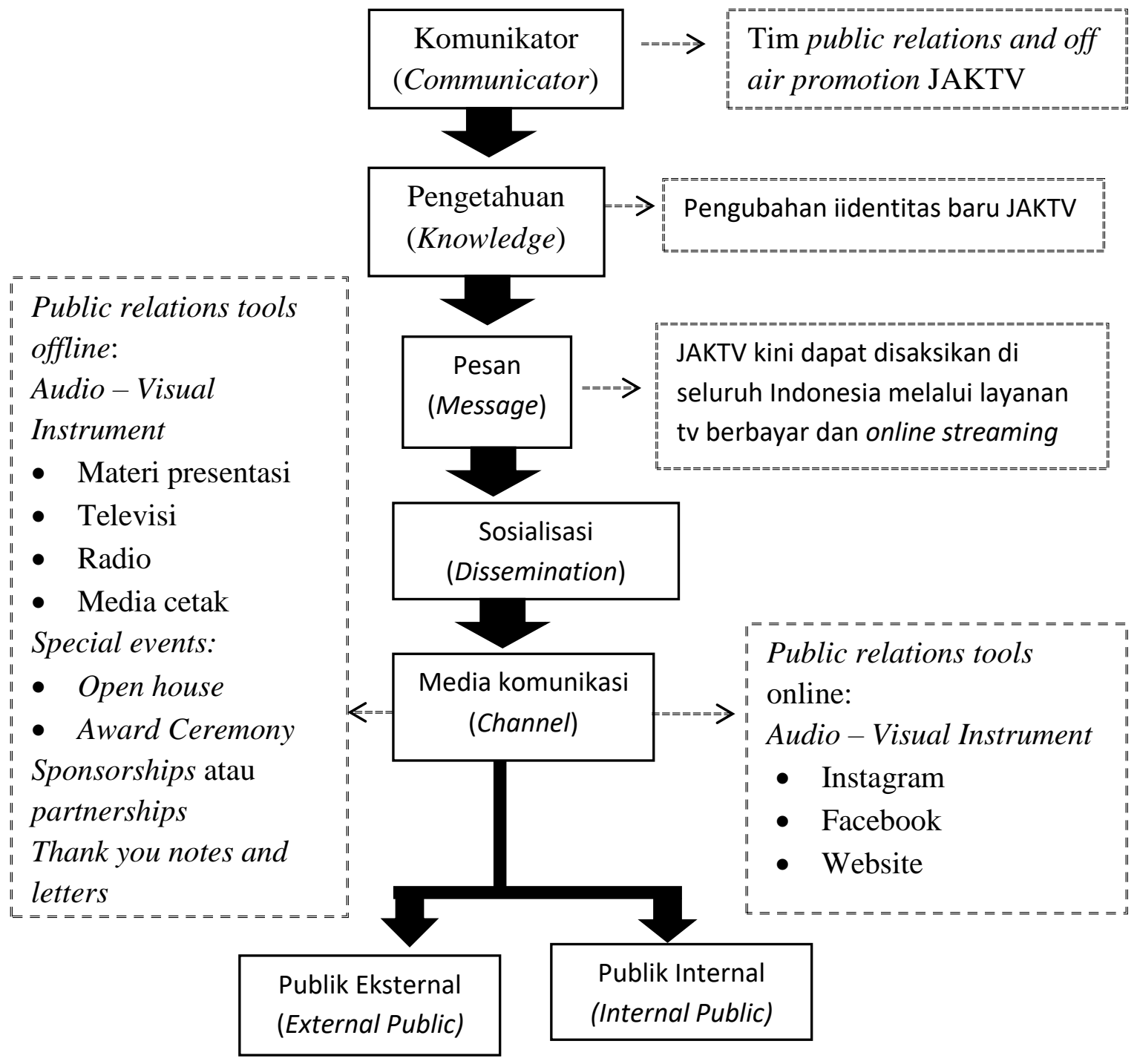

\section{Kesimpulan}

Proses sosialisasi identitas baru JAKTV ini terjadi akibat dari upaya repositioning JAKTV terhadap target market dan citra perusahaan, yang mana JAKTV ingin mempertegas positioning bahwa kini JAKTV bukan lagi brand yang dimiliki oleh masyarakat sekitar Jakarta saja namun JAKTV menjadi sebuah brand yang dimiliki seluruh Indonesia.

Proses sosialisasi ini direncanakan dengan menerapkan konsep dari The $7 C$ 's of Communication yang memiliki beberapa elemen yaitu (1) kredibilitas atau credibility, (2) konteks atau context, (3) konten atau content, (4) kejelasan pesan atau clarity, (5) kesinambungan isi pesan dan konsistensi atau continuity and consistency, (6) media komunikasi atau channel, dan (7) 
kemampuan audience atau capability of the audience, untuk dapat menghasilkan proses komunikasi yang efektif dalam menyosialisasikan pesan yang terkandung dalam identitas baru JAKTV.

Dari hasil penelitian ini dapat disimpulkan bahwa repositioning yang dilakukan oleh JAKTV ini bertujuan untuk mempertegas posisi JAKTV bahwa JAKTV ingin dikenal tidak lagi sebagai brand yang dimiliki oleh masyarakat sekitar Jakarta saja namun sebagai sebuah brand dan televisi yang dimiliki oleh seluruh masyarakat Indonesia serta guna mengakomodasi hasil evaluasi yang telah dilakukan oleh JAKTV, dimana hasil dari evaluasi tersebut memperlihatkan bahwa terhadap perluasan jumlah sebaran audience yang menyaksikan tayangan JAKTV sehingga perluasan pangsa pasar pun turut dilakukan untuk memperlihatkan bahwa dengan keadaan pasar yang semakin berkembang, JAKTV mampu untuk tetap terus mengikuti permintaan audience.

Dalam melakukan sosialisasi pengubahan logo dan tagline JAKTV, tim dari Public Relations and Off Air Promotion Department telah menerapkan berbagai taktik public relations sebagai upaya atas sosialisasi identitas baru JAKTV yang di akibatkan dari usaha repositioning target market dan citra perusahaan dengan memanfaatkan berbagai taktik yaitu public relations tools yang terdiri dari 1) Open house atau company visit; 2) Award ceremony; 3) Audio- visual instrument; 4) Thank you notes and letters; 5) Sponsorships atau partnerships.

Setelah dilakukan proses pengevaluasian terhadap proses sosialisasi identitas baru JAKTV, maka dapat di katakan bahwa proses sosialisasi ini membawa pengubahan dalam kevariatifan kepemirsaan JAKTV. Hal ini terlihat dari $60 \%$ porsi pemberitaan di Jakarta berskala nasional sehingga pemirsa yang menyaksikan tidak hanya berasal dari Jakarta saja.

Proses sosialisasi identitas baru JAKTV sebagai akibat dari repositioning target market dan citra perusahaan ini pun berhasil membuat JAKTV mendapatkan penghargaan sebagai televisi lokal peringkat rating pertama di Jakarta dengan pemirsa terbanyak pada Desember 2018 hingga April 2019 yang diberikan oleh AC Nielsen.

Disarankan agar peneliti selanjutnya dapat melakukan penelitian mengenai persepsi dari target publik JAKTV terhadap repositioning JAKTV dari My City My Tv menjadi Dari Jakarta untuk Indonesia guna melihat hasil dari proses repositioning yang telah dilakukan . 


\section{DAFTAR PUSTAKA}

\section{Book}

Creswell, J.W. (1994). Research Design: Qualitative \& Quantitative Approacher. Chicago, United States of America: Sage Publications

Cohen. L., Manion. L., \& Morrison. K. (2007). Research Methods In Education (6 ed.). New York, United States of America: Routledge.

Cutlip, S.M., Center, A. H., Broom, G.M. (2011). Efective Public Relations. Jakarta, Indonesia: Kencana.

Danim, S. (2000). Metode Penelitian Untuk Ilmu-Ilmu Perilaku: Acuan Dasar Bagi Mahasiswa Program Sarjana Dan Peneliti Pemula. Jakarta, Indonesia: Bumi Aksara.

Eriyanto. (2004). Analisa Framing: Konstruksi, Ideologi, Dan Politik Media. Yogyakarta, Indonesia: LKiS.

Kriyantono, R. (2012). Public Relations Writing :Teknik Produksi Media Public Relations dan Publisitas Korporat. Jakarta, Indonesia: Kencana Prenada Media.

Miles, M. B., Huberman, A. M., \& Saldana, J. (2014). Qualitative Data Analysis (3 ed.). United States of America: SAGE.

Neuman, W. L. (2014). Social Research Methods: Qualitative And Quantitative Approaches. (Eds 7). Harlow, United Kingdom: Pearson Education Limited

Sugiyono. (2013). Metode Penelitian Kuantitatif, Kualitatif Dan R\&D. Bandung, Indonesia: Alfabeta

\section{Journal articles}

Shesarria, G., Gitasiswhara. (2012). Pengaruh Strategi Repositioning Holiday Inn Bandung Terhadap Kepercayaan Tamu Member, Tourisim and Hospitality Essential Journal, 2(2), p.339-361

Yusiana, R. \& Maulida, R. (2015, April). Pengaruh Gita Gutawa Sebagai Brand Ambassador Pond's

Dalam Mempengaruhi Keputusan Pembelian (Studi Kasus Pada Mahasiswi Universitas Telkom Jurusan D3 Manajemen Pemasaran), Ecodemica, 3(1), p.311 - 316.

\section{Online articles}

Dahwilani, D. M. (2018, Februari 22). Perkuat Bisnis Danone-Aqua Gunakan Logo dan Slogan Baru. Diakses dari https://ekbis.sindonews.com/read/1284393/34/perkuat-bisnis-danoneaqua-gunakan-logo-dan-slogan-baru-1519309709.

Purbalingga Sehati Dilaunching, Purbalingga Tidak Lagi Perwira (2017, July 18). Diakses dari https://banyumasnews.com/96506/purbalingga-sehati-

dilaunching-purbalingga-tidak-lagi-perwira/.

Ridlo, M. (2017, Juli 20). Slogan Sehati Kreasi Bupati Purbalingga Malah Undang ProKontra. Diakses dari https://www.liputan6.com/regional/read/3028892/slogan-sehati-kreasibupati-purbalingga-malah-undang-pro-kontra. 
Rita. (2015, May 15). Sukseskah Rerbanding Tokobagus MenjadiOLX?. Diakses dari https://sbm.binus.ac.id/2015/05/15/ sukseskah-rebranding-tokobagus-menjadi-olx/.

Satryatomo , T. (2017, Maret 18). Menata Industri Penyiaran Yang Sedang Berubah. Diakses dari https://nasional.sindonews.com/read/1189479/18/

Wulandari, D. (2014, November 25). 10 Rebranding Campaign Paling Sukses. Diakses dari http://mix.co.id/headline/10-rebranding-campaign-paling-sukses. 